\title{
Thailand Ranks Second in the World for Number of Road Accidents under Thailand's Codes of Geometrical Design and Traffic Engineering Concept When Compared with AASHTO
}

\author{
Weeradej Cheewapattananuwong \\ Bureau of Road Design, Department of Rural Road, 9 Paholyothin Rd, Bangkhen Bangkok Thailand \\ Faculty of Engineering, Thummasat University (Rangsit Campus), Bangkok, Thailand
}

\begin{abstract}
Traffic problems in Bangkok have an influence on road users during peak hours. Especially, the traffic bottleneck on curves under the saturation flow situation must be remedied in order to increase the roadway capacity and speed. However, the appropriate speed for heavy vehicles is taken into consideration during off peak after the increasing lanes. This leads to the Rollover of heavy truck and rear-end collisions which are the main causes of vehicles accidents on curves. In addition, road accidents on curves account for the majority of all accidents in Thailand. According to the road accidents data collected in Thailand, 44 road deaths per 100,000 people, the country ranks second in the world for road accidents. When Thailand's Code of Geometrical Design is compared with AASHTO (The American Association of State Highway and Transportation Officials), the super elevation length of Thailand's Code is more than AASHTO. As a result, drivers are not made aware of the appropriate speed and the stooping sight distances (SSD) on curves. Therefore, the Design of Traffic Signage under the Perception and Reaction Times (PRT) for Thai Drivers will be taken into account.
\end{abstract}

\section{Introduction}

The Development of ITS (Intelligent Transportation System) has been developed since 2009. Image Sensing Technique by VLD (Virtual Loop Detector) for Checking Speed of Vehicles and LPR (License Plate Recognition) for Traffic Classified Counts in Thailand are taken into account. The traffic volumes on road curve are over saturation situation or F - Level of Service (L.O.S.). In case of Roadway Capacity, the increasing lanes on curve are taken into consideration. Although the traffic problem can be solved by this method, the over speed on curve must be controlled and the appropriate speed needs to be informed to drivers by the warning signage. In addition, the researcher is concerned with the geometrical design factors such as, super-elevation length on curves and Stopping Sight Distances (SSD) of PRT for Thai drivers. The Traffic Signage will also be calculated and installed on curved roads under the design factors as mentioned above. However, the number of traffic accidents on curves rises dramatically when Super Elevation Length of Thailand's Codes is more than AASHTO's Length. This is owing to the fact that sizes of letters on the traffic signage have an effect on road users.

\section{Traffic collected data by ITS}

There are two cases of applied ITS for collected data. One is a measurement of vehicle speed and the other is vehicle classification count by LPR off-line method as described in the following paragraph.

\subsection{Image processing concept}

FG/BG Detection module performs foreground/ background segmentation for each pixel. Blob Entering Detection module uses the result (FG/BG mask) of FG/BG Detection module to detect new blob object entered to a scene on each frame. Blob Tracking Module initialized by Blob Entering Detection results and tracks each new entered blob. Trajectory Generation module performs a saving function. It collects all blobs positions and saves each whole blob trajectory to hard disk when finished. Trajectory post processing module performs a blob trajectory smoothing function. The application of Blob Entering Detection Techniques is shown in Fig. 1.
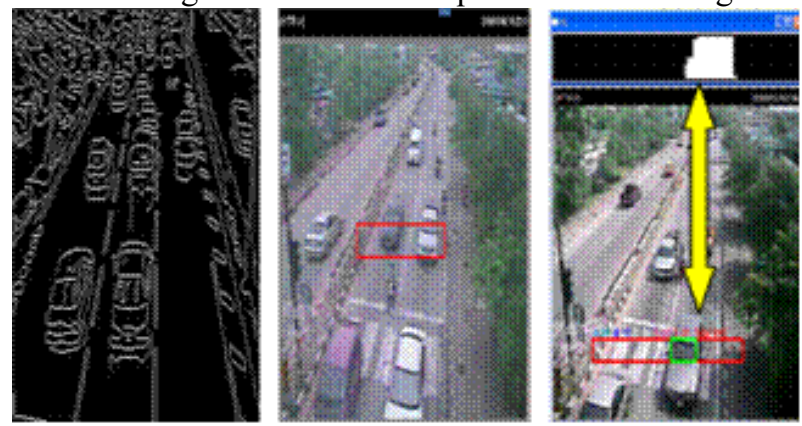

Figure 1. Results of the Application of Blob Entering Detection Techniques. 


\subsection{Measurement of speed}

The positions of Lane Changing, which are 3 points, are located on Fig. 2. The first curve of Lane Changing and Speed of circular curve is composed of coordinates among points $(\mathrm{x} 1, \mathrm{y} 1),(\mathrm{x} 2, \mathrm{y} 2)$, and $(\mathrm{x} 3, \mathrm{y} 3)$ respectively. The calculation of angle, length of Lane Changing and speed used the concepts of geometrical design under the specific times as shown in Fig. 2 and Fig. 3.

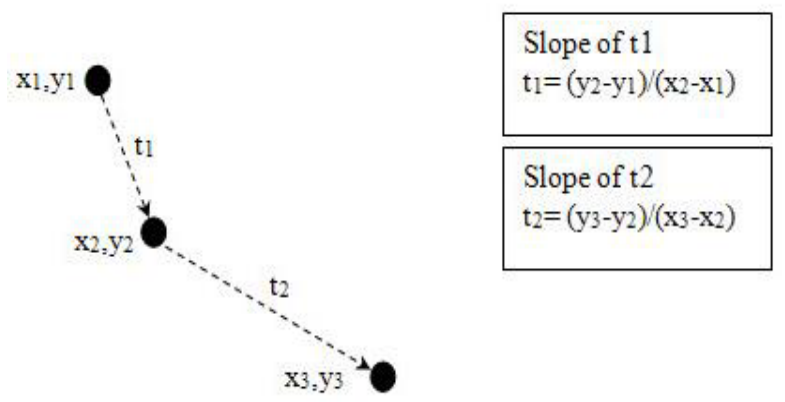

Figure 2. Three points of lane changing and speed concept.

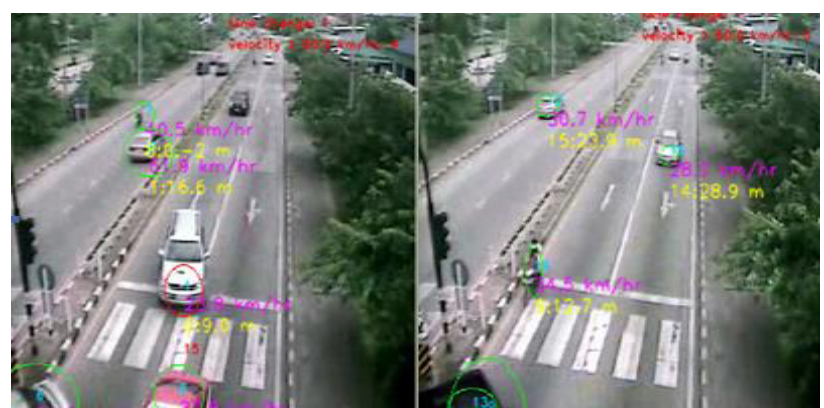

Figure 3. Speed of each vehicle.

\subsection{LPR}

There are 22 types of classified vehicles [4]. In case of the accuracies of LPR Classified Counting at night time, it is not clear to read the number of license plate, although the researchers choose both high resolution of optical lens $(50 \mathrm{~mm})$ and the zero LUX of CCTV. The Traffic Volumes on Curve during peak hour is 684 vehicles per hour and the average speed is $13 \mathrm{KPH}$ (L.O.S - F). This is due to the fact that the saturation flow from next intersection (Bromrajchonne Road) has an influence on this road as presented in the Fig. 4.

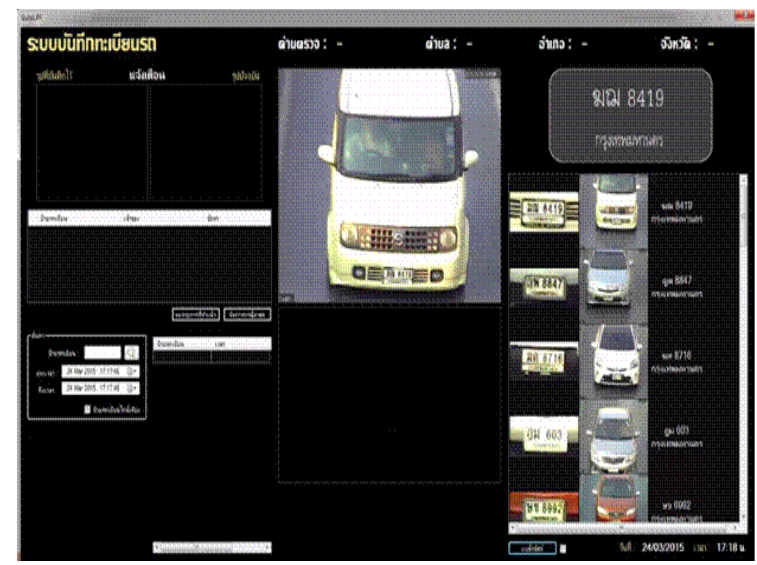

Figure 4. Traffic classified survey by LPR method.

\subsection{Traffic collected data and evaluated existing situation}

The Existing Traffic Volumes from LPR Method are input in the Trafficware Software [7]. As a result, the traffic situation is a stop and go model as presented in Fig. 5.

SimTraffic Performance Report

Baseline

$207 / 2015$

\begin{tabular}{lr}
\hline Total Network Performance & \\
\hline & \\
\hline & 1892 \\
\hline Total Delay (hr) & 3743 \\
Delay / Veh (s) & 1859 \\
Total Stops & 1308.1 \\
Travel Dist (im) & 198.0 \\
Travel Time (hr) & 13 \\
Avg Speed (hoh) & 5572 \\
Fuel Uyed (I) & 352 \\
HC Emisions (g) & 7188 \\
CO Emissions (g) & 679 \\
NOx Emissions (g) & 1769 \\
Vehides Entered & 1485 \\
Vehides Exited & 8910 \\
Hourly Exit Rate & 185 \\
Denied Entry Before & 1151 \\
Denied Entry After &
\end{tabular}

Figure 5. Traffic factors on curve (Exit Ramp) before situation.

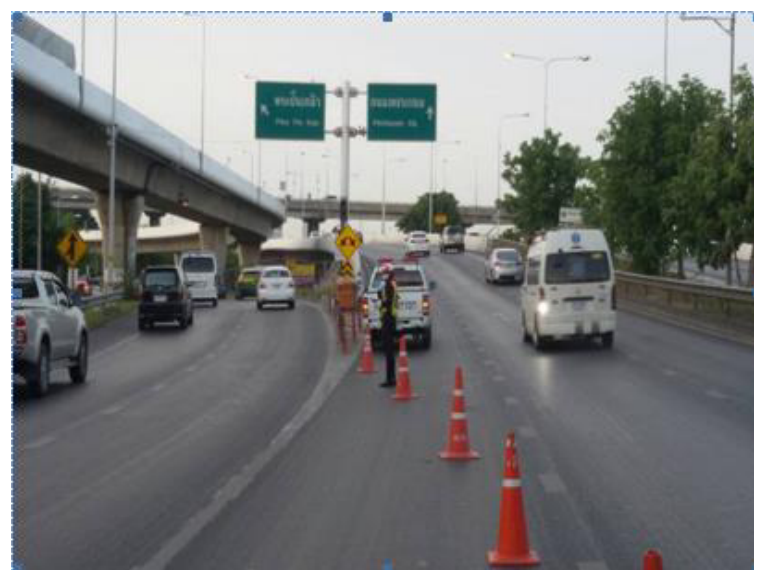

Figure 6. Increasing of lane capacity on curve.

SimTraffic Performance Report Baseline $20 / 7 / 2015$

Total Network Performance

\begin{tabular}{lr|}
\hline & \\
\hline Total Delsy (hr) & 157.8 \\
Delay / Veh (s) & 338.9 \\
\hline Total Stops & 2874 \\
Travel Dist (km) & 1538.2 \\
Travel Time (hr) & 191.4 \\
Avg Speed (chh) & 19 \\
Fuel Used (1) & 587.6 \\
HC Emissions (g) & 358 \\
CO Emissions (g) & 7526 \\
NOx Emissions (g) & 722 \\
Vehides Entered & 1809 \\
Vehides Exited & 1583 \\
Hourly Exit Rate & 9378 \\
Denied Enty Before & 194 \\
Denied Enty After & 1140 \\
\hline
\end{tabular}

Figure 7. The raised speed after mitigation.

\section{Roadway capacity and number of lanes on curve (exit lane)}

Roadway Capacity is very important for Highway Planners when considering traffic lanes on curve [6]. The solution of this case study is to increase the number of lanes from 2 lanes to 3 lanes as can be seen in the Figure 
3. However, the road width is lower than the standard lane $(3,5 \mathrm{~m})$. For example, the comparison of lane capacity between $3.5 \mathrm{~m}$ and $3.0 \mathrm{~m}$ of lane width are 1,288 and 1,261 vehicles/hour/lane or 2,575 vehicles/hour/2Lanes $(3.5 \mathrm{~m})$ and 3,783 vehicles/hour/3Lanes $(3.0 \mathrm{~m})$ respectively. Therefore, the increasing of roadway capacity is tested on curve to improve the traffic flow. As a result, it can also raise the average speed of vehicles when driving on curve (see Fig. 6, Fig. 7).

\section{The geometrical design factors on curve}

There are two Geometrical Design Factors as compared between Thailand's Codes and AASHTO. The Super Elevation Length on Curve and Stopping Sight Distances lead to the traffic accidents and these factors under Thailand's Codes are of higher values than AASHTO. Furthermore, Fatalities in Thailand rank second out of all the road accidents in the world, which is the rate of 44 road deaths per 100,000 people in Thailand. The first Ranking of 45 road deaths per 100,000 occurs in Namibia [1]. The traffic factors will be described in the following parts.

Source : [3]

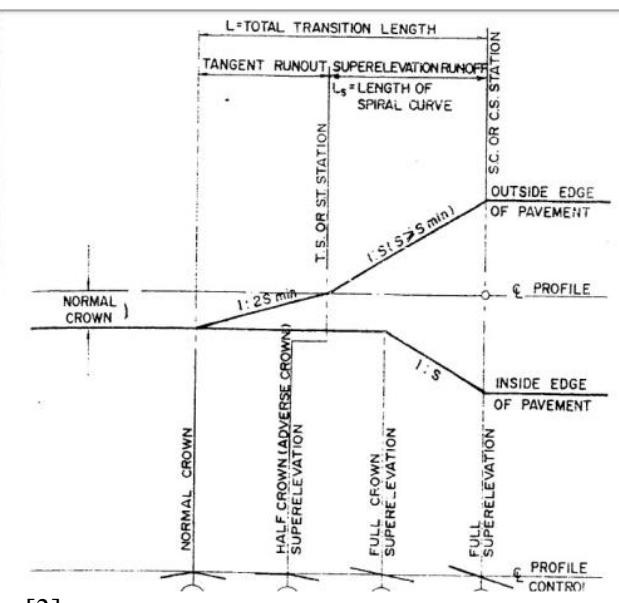

Figure 8. Super elevation length of AASHTO.

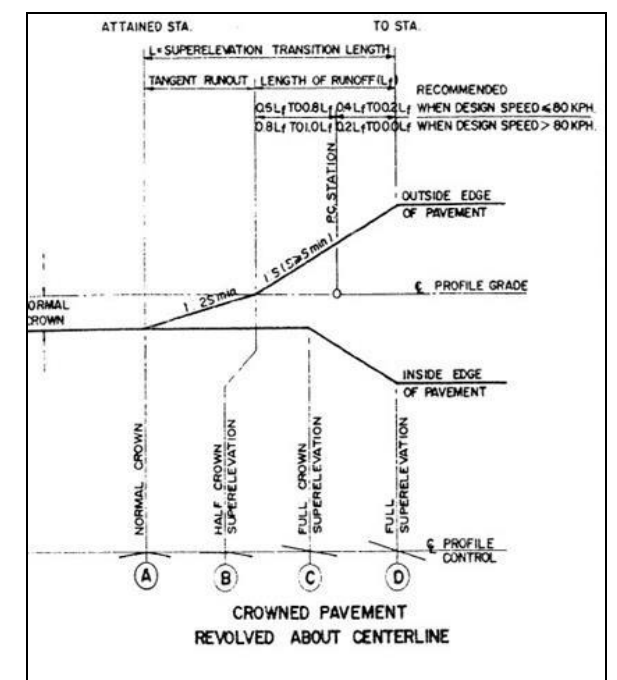

Source : [2]

Figure 9. Super Elevation Length of Thailand's Code.

\subsection{Super elevation curve length}

The comparison of Super Elevation between AASHTO and DRR (Thailand's Codes) will be described in the Fig. 8, Fig. 9 and Table 1, Table 2 and Table 3.

Table 1. Comparison between super elevation length of Thailand's code and AASHTO.

\begin{tabular}{|c|c|}
\hline Thailand's Code & AASHTO \\
\hline $\left.\mathrm{Lf}=\mathrm{HC}^{*} \mathrm{~s}+\left(\mathrm{e}^{*} \mathrm{~W} / 2\right)-\mathrm{HC}\right)^{*} \mathrm{~s}$ & $\mathrm{Lf}=\left(\left((\mathrm{wn} 1)^{*} \mathrm{ed} / \delta\right)^{*} \mathrm{bw}\right.$ \\
\hline $\mathrm{Lt}=\mathrm{HC}^{*} 2 * \mathrm{~s}$ & $\mathrm{Lt}=(\mathrm{enc} / \mathrm{ed}) * \mathrm{Lf}$ \\
\hline 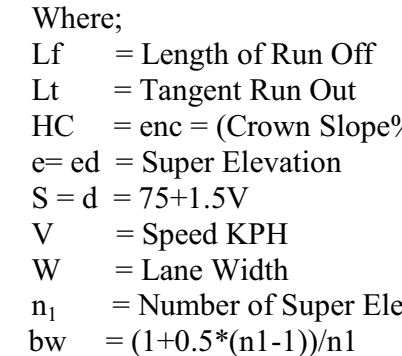 & $/ 100)^{*}$ Lane Width/2 \\
\hline
\end{tabular}

Table 2. Results of super elevation length of Thailand's Code.

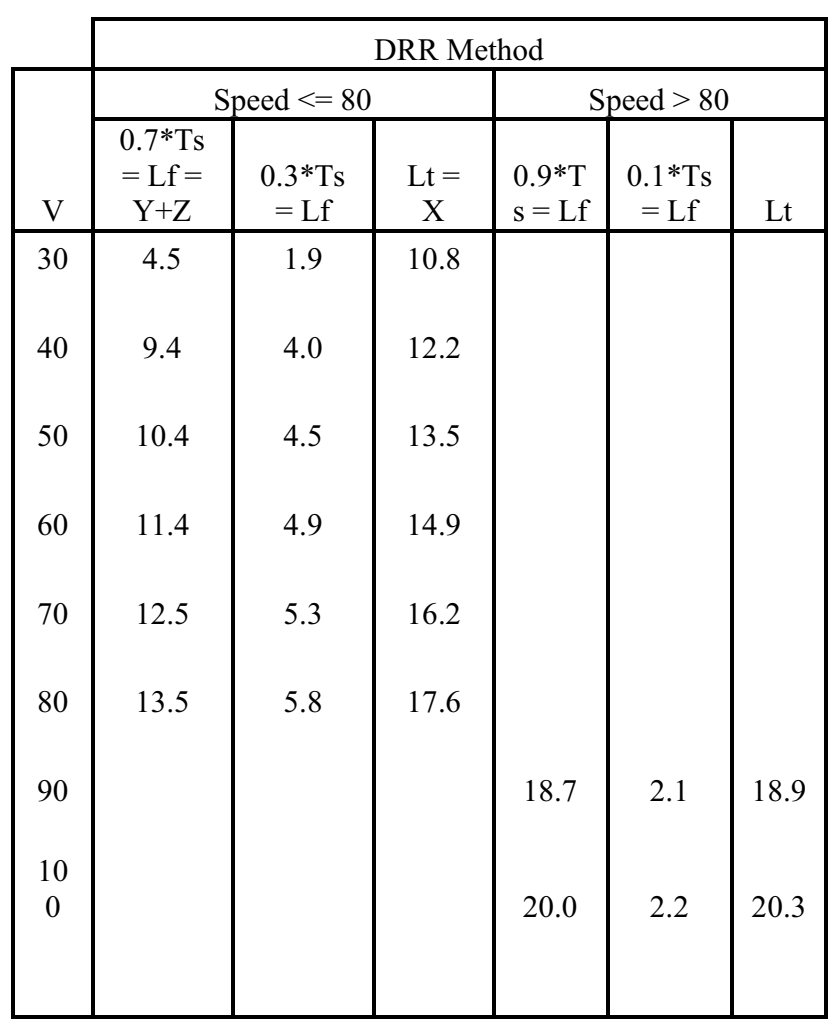

Table 3. Results of super elevation length of AASHTO.

\begin{tabular}{|c|c|c|c|c|c|c|}
\multicolumn{7}{c|}{ AASHTO Method } \\
\hline \multirow{2}{*}{} & \multicolumn{3}{|c|}{ Speed $<=80$} & \multicolumn{3}{|c|}{ Speed $>80$} \\
\cline { 2 - 7 } $\mathrm{V}$ & $\begin{array}{c}0.7 * \mathrm{Ts} \\
=\mathrm{Lf}\end{array}$ & $\begin{array}{c}0.3 * \mathrm{Ts} \\
=\mathrm{Lf}\end{array}$ & $\mathrm{Lt}$ & $\begin{array}{c}0.9 * \mathrm{Ts} \\
=\mathrm{Lf}\end{array}$ & $\begin{array}{c}0.1 * \mathrm{Ts} \\
=\mathrm{Lf}\end{array}$ & $\mathrm{Lt}$ \\
\hline 30 & 4.5 & 1.9 & 10.8 & & & \\
40 & 5.1 & 2.2 & 12.2 & & & \\
50 & 5.7 & 2.4 & 13.5 & & & \\
& & & & & & \\
\hline
\end{tabular}




\begin{tabular}{|c|l|l|l|l|l|l|}
\hline 60 & 6.2 & 2.7 & 14.9 & & & \\
70 & 6.8 & 2.9 & 16.2 & & & \\
80 & 7.4 & 3.2 & 17.6 & & & \\
90 & & & & 7.9 & 3.4 & 18.9 \\
10 & & & & 8.5 & 3.6 & 20.3 \\
0
\end{tabular}

As can be seen from the above Tables, the Length of Curve $-\mathrm{Y}+\mathrm{Z}$ in the case of Thailand's Codes is dramatically more than AASHTO. However, the length of X in case of Thailand's Codes is equal to AASHTO. In case of C.G. of Vehicle, the Running Speed during testing with C.G. Equipment is illustrated in Fig. 10 and Fig. 11.

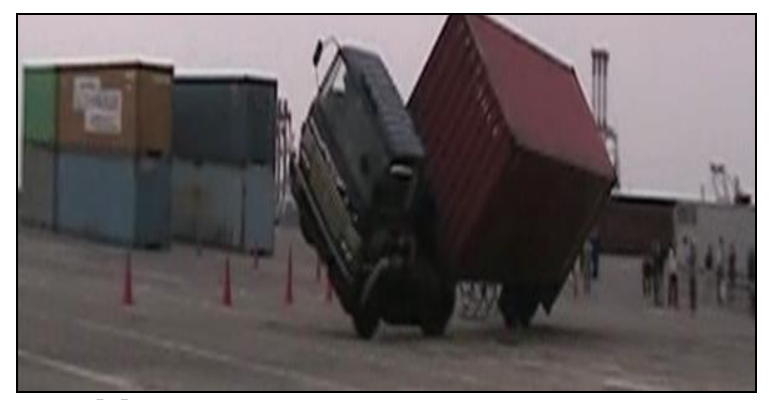

Source : [5]

Figure 10. mSuper Speeding of a Test Vehicle under the Standard Radius.

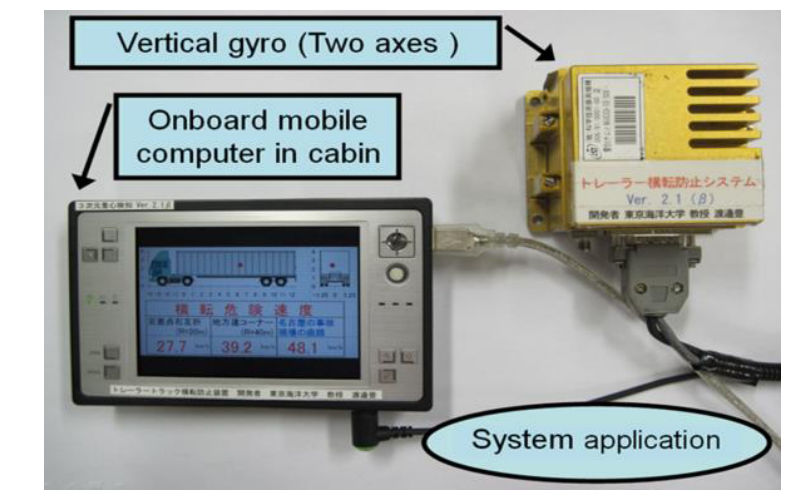

Source : [5]

Figure 11. C.G. Equipment.

During the testing, a trailer was tested with the C.G. equipment and the critical speed or Safety Speed was lower than the design speed. The Safety Equation is presented in the next equation.

Safety Speed $=44.6153846153846+$ $14.1862550031749 * \sin (0.805821839123194$ / $\operatorname{asinh}(\bmod (($ Design Speed, km/hr), 0.987455336652175))

+ delay ((Design Speed, $\mathrm{km} / \mathrm{hr}), 5)+$ erf(sin(1.78663889085124 - delay((Design Speed, km/hr), 3)))) - $9.15707764551099 * \cosh (\bmod ($ delay $(($ Design Speed, $\mathrm{km} / \mathrm{hr}), 1), 1.2422838109887)$ ) * mod(1.17493434602731, $\bmod (($ Design Speed, $\mathrm{km} / \mathrm{hr})$, $0.793435970498463)) * \cosh (\bmod ($ delay $((D e s i g n$ Speed, $\left.\mathrm{km} / \mathrm{hr}), 1), 1.2422838109887)^{\wedge} 1.95733458837149\right) \quad$ (1)

$\mathrm{R}^{\wedge} 2$ Goodness of Fit $=0.89883218$ and Correlation Coefficient $=0.95710217$

\subsection{Stopping sight distances (SSD)}

According to Running Speed, the researcher will give the Safety Speed of Heavy Vehicle as based on Equation (2, 3 and 4). For example, the Design Speed is about $60 \mathrm{KPH}$ and the Safety Speed will be $44 \mathrm{KPH}$. Therefore, the installation of traffic signs and sizes of letters will be located before the point of curve (PC) as described in the following parts.

4.2.1 Formatting the title concept of PIEV (Perception, Interpretation, Emotion and Volition and SSD (See Figure 12). $L=0.278^{*} V^{*} T$

$$
\begin{gathered}
A=6.30442+(0.08586 * V)+(7.44363 e-10) * V 5 \\
K=0.278 * \text { PIEV Time } \\
S S D=0.896671 * V f 2
\end{gathered}
$$

where;

$\mathrm{L}=$ Reading at the Meaning (0.88 seconds) of Traffic Sign - Distance and Reading Time (2 Syllable per second) $\mathrm{A}=$ Acute Angle of Driver's Vision - Distance $\mathrm{K}=$ PIEV (2.5 Seconds) Distance $\mathrm{SSD}=$ Stopping Sight Distance $\mathrm{V}=$ Running Speed $\mathrm{V}_{\mathrm{f}}=$ Final Running Speed

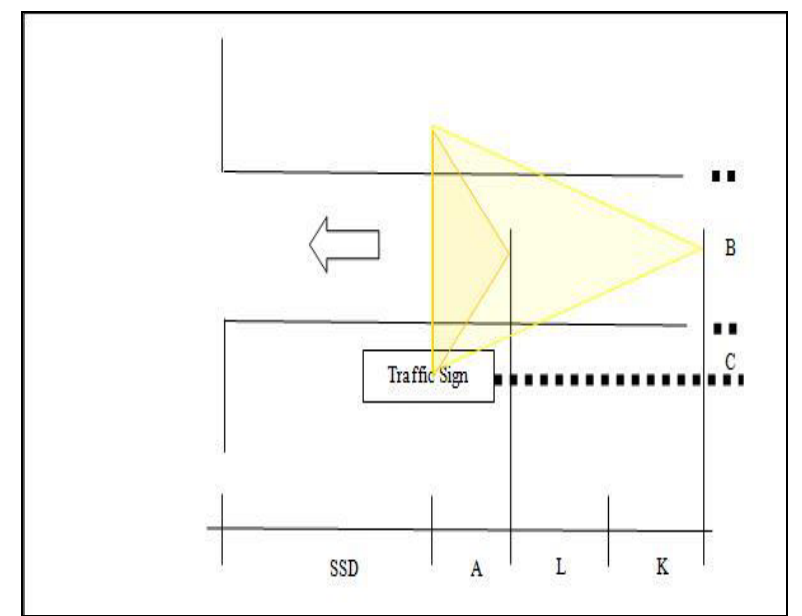

Figure 12. L, A and K Distance for Reading the words in the Traffic Sign.

\subsubsection{Concepts of sizes of letters in traffic sign}

$$
\begin{gathered}
H=1.3+0.195 *[(L+A+K)+0.139 * V * N] \\
T=H / 6 \\
N=[(H-1.3) / 0.195-(L+A+K)] /(0.139 * V)
\end{gathered}
$$

where;

$\mathrm{H}=$ Height of Letters $(\mathrm{cm}$. 
$\mathrm{T}=$ Thick of Letters $(\mathrm{cm}$.

$\mathrm{N}=$ Syllable

The Table 4 presents $30 \mathrm{~cm}$. of Height, Thickness and Syllable of Letters in a Traffic Sign at various Running or Safety Speed. For example, speed at urban area (60 KPH) will be proposed $30 \mathrm{~cm}$. of letters, two rows of Letters with 5 Syllables per row at a traffic sign under 101.77 meters of the $\mathrm{L}+\mathrm{A}+\mathrm{K}$ Distances.

Table 4. $30 \mathrm{CM}$, Height, thickness and syllable of letters on traffic sign based on speed.

\begin{tabular}{|c|c|c|c|}
\hline Height $=$ & 30 & $\mathrm{~cm}$ & \\
\hline Speed & $\mathrm{L}+\mathrm{A}+\mathrm{K}$ & $\mathrm{N}$ & Level \\
\hline 30 & 54.00 & 22 & 7 \\
\hline 40 & 70.00 & 14 & 5 \\
\hline 50 & 86.00 & 9 & 3 \\
\hline 60 & 102.00 & 5 & 2 \\
\hline 70 & 119.00 & 3 & 1 \\
\hline 80 & 136.00 & 1 & 0 \\
\hline 90 & 153.00 & 0 & 0 \\
\hline 100 & 172.00 & -2 & -1 \\
\hline 110 & 209.00 & -4 & -1 \\
\hline
\end{tabular}

\section{Mitigation of traffic accidents}

Thai drivers use the SSD which is lower than the SSD of ASSHTO as based on the Equation (2, 3 and 4). Therefore, the Traffic Signage by ITS can warn Thai's Drivers to increase the length of SSD in order to operate their vehicles safely by using VMS (Variable Message Sign) as described in Fig. 13 and Table 5.

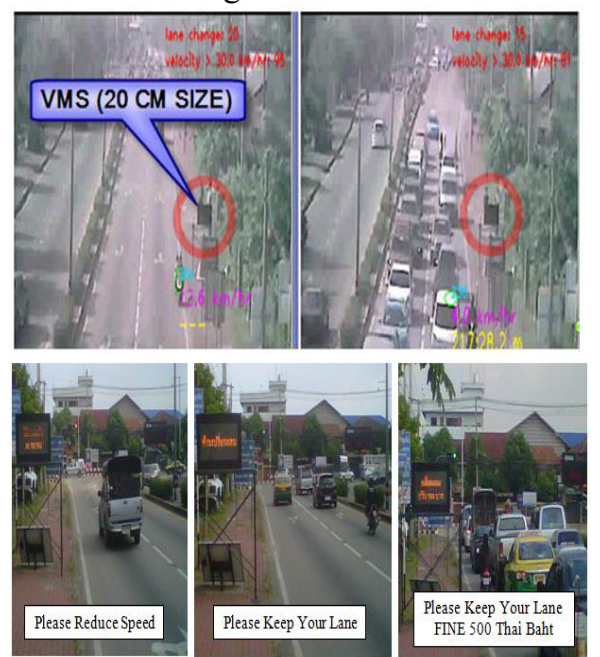

Figure 13. Controlled Speed by the Size of Letter in Variable Message Sign (VMS).
Table 5. 7 Collected Traffic Changing Lane and Speed Data during Installed VMS.

\begin{tabular}{|c|c|c|c|}
\hline $\begin{array}{c}\text { Mitigation } \\
\text { Scenarios }\end{array}$ & $\begin{array}{c}\text { Number of } \\
\text { Lane Changing } \\
\text { Vehicles }\end{array}$ & $\begin{array}{c}\text { Number of } \\
\text { Over Speed } \\
\text { Vehicles }\end{array}$ & $\begin{array}{c}\text { Decreasing } \\
\text { Percentage } \\
(\%)\end{array}$ \\
\hline W/O VMS & 47 & 192 & $-38.30,27.60$ \\
\hline $\begin{array}{c}\text { Wt VMS } \\
\text { «No Fine » }\end{array}$ & 29 & 139 & $-62.45,-38.54$ \\
\hline $\begin{array}{c}\text { Wt VMS } \\
\text { «Fine» }\end{array}$ & 20 & 118 & \\
\hline
\end{tabular}

\section{Conclusion}

The increasing of traffic volumes by the decreasing of normal lane width and the increasing of lanes from 2 lanes to 3 lanes are taken into consideration. In addition, the application of Thailand's Code for Road - Curve Design Length is longer than AASHTO. However, the number of Traffic Accidents has substantially increased. The important mitigation is to install traffic signage and to focus on various sizes of letters when compared with speed. This is pointed out in the message on the traffic sign to warn drivers to drive on curve safely. Strict and Severe Law Enforcement is the best solution for Thai people who disobey the traffic laws. The researcher wishes to decrease the number of accidents as soon as possible.

\section{References}

1. Asian Correspondent, Study: Thailand's roads 2nd most dangerous in the world, https://asiancorrespondent.com/2014/02/studythailand-roads-2nd-most-dangerous-in-theworld/,(2014).

2. CALTRANS, Highway Design Manual, California Department of Transport, California, (1995)

3. Department of Rural Roads, Standard of Super Elevation, Ministry of Transport, Bangkok, (2014)

4. Land Transport Department. Vehicle License Plate ACT. (1979).

5. Y. Watanabe, Detection of three Dimension Centre of Gravity (D3DCG), Tokyo University of Marine Science and Technology, Managed by Japan Association of D3DCG. (2014).

6. Transport Road Board (TRB), Highway Capacity Manual, fifth edition, (2010).

7. Trafficware Synchro Version 6, Traffic Engineering and Simulation Software (1993-2005), (2005). 